\title{
INTEGRATION OF SAFETY ASSESSMENT IN BIM FOR TRANSPORTATION INFRASTRUCTURE
}

\author{
Z. Svatý ${ }^{1, *}$, K. Kocián ${ }^{1}$, T. Mičunek ${ }^{1}$ \\ ${ }^{1}$ CTU in Prague, Faculty of Transportation Sciences, Department of Forensic Experts in Transportation, Horska 2040/3, \\ 12800 Prague - (svaty / kocian / micunek)@ fd.cvut.cz
}

\section{Commission V, WG V/7 \& Commission IV, WG IV/6}

KEY WORDS: Building information model, Road infrastructure, Road safety, Road safety inspection, Operation and Maintenance

\begin{abstract}
:
Effective and safe transportation infrastructure presents one of the crucial conditions for functional society. Its ceaseless development and construction can be taken as a proof of its importance even despite the corresponding financial and time demands. The complexity and scale of the projects related to transportation infrastructure presents an ideal field for implementation of the BIM approaches. However, it is necessary to implement the BIM to the whole life cycle of the transport structure, especially not only to the preinvestment and investment phases but also to the operation and maintenance. For every road infrastructure, it is important to observe the performance of the road, behaviour of road users and evaluate the resulting safety risks, to be able to correspond with adequate and effective measures and to secure sufficient level of safety. The paper aims to present an implementation of the road safety aspects and statistics into the processes of BIM applications and strategies, which are prepared on the base of Government Resolution No 958, on the importance of the Building Information Modelling (BIM) in the Czech Republic. The accident statistics, safety audits and inspections presents a valuable source of information that should be adequately implemented with the BIM processes.
\end{abstract}

\section{INTRODUCTION}

Transportation infrastructure presents a key role in social and economic development of all countries and applying new methods for improving their design and operation should be desired. While the implementation of building information modelling (BIM) has become a central topic to the improvement of the AECOO (Architecture, Engineering, Construction, Owner and Operator) industry around the world, the usage of BIM broaden and is nowadays applied to the civil infrastructure. However, the concept of BIM was initially designed for application in building sector. The transition has to overcome several limitations and adapt to slightly different environment and processes.

It is believed that the use of BIM in infrastructure is several years behind from its use for buildings, but evidence show that recently the use of BIM in civil infrastructure is steadily rising (AlMashta, Alkass, 2010). An increasing number of European governments and public sector agencies are setting up programmes to promote wider use of BIM at national and regional levels. Government policies and public procurement provide significant support to motivate positive changes in the sector. There is a significant growth in adoption of BIM for infrastructure since 2012 in Europe, and the rate of BIM implementation for infrastructure projects is steadily increasing (Gökçe et al., 2006). This article focuses mainly on the implementation of BIM in the Czech Republic. The Czech government is trying to follow the lead of other European countries and it is developing BIM strategies, which are prepared on the base of Government Resolution No 958, on the importance of the BIM in the Czech Republic (IEG BIM, 2017).

The development of standards and procedures is in its initial period and focuses mainly on the pre-investment and investment phases of the projects. However, based on the Government Resolution, after the year 2022 the BIM will be applied to whole life cycle of the assets. Therefore, it is necessary to focus on the remaining aspects of the building life cycle. The necessity is stressed by the fact, that in cases of road infrastructure, where are newly designed long-live or even perpetual pavements, the operation phase is carried over long periods of time and is usually connected with significant costs and gradual development of the road itself (Ferne B., 2006). Furthermore, for road infrastructure it is important to observe the performance of the road, behaviour of road users and evaluate the resulting road safety risks, to be able to correspond with adequate and effective measures. The maintenance and operation phase of road life cycle involves not only slight changes in road equipment or gradual replacement of worn-out parts but also changes of the road spatial layout due to additional influences, e.g. identification of more suitable layout of intersections, introduction of new lanes to improve the resulting level of road safety, etc. Thus, the aim of this paper is to present an implementation of the road safety aspects and statistics into the processes of BIM applications and strategies to enable efficient and effective measures and to secure sufficient level of safety.

\section{BIM FOR ROAD INFRASTRUCTURE}

The implementation of BIM concept for civil infrastructure, especially road network, presents an expansion into domain where it was not originally conceived to address. The advantage of use of BIM for troad infrastructure, where the graphical designs are already widely use, lies mainly in coordination and visual integration of non-graphical data into the models. BIM models can store considerable amount of information through the life cycle of the infrastructure (See et al, 2012).

\footnotetext{
* Corresponding author
} 
As with any BIM approach, the effectiveness and usefulness of the data is dependent on the ability to specify what data should be collected, who will be responsible for their collection and how it will be utilised, along with the provision of technologies to capture and transfer the data between participating parties (Bradley et al., 2016).

Many common features are shared between buildings and transportation infrastructure from the perspective of BIM implementation. However, there are several differences in a way, how they are designed and subsequently managed.

In transport construction, interconnected line construction works are used, unlike in the case of building construction that are dominated by point structures located on a concentrated area with a more complex internal arrangement. An important specific aspect of transport structures is their spatial location and the need to manage information models as a complex geographic data. Spatially organized information is necessary in all phases for planning, designing, constructing, operating, and maintaining of transportation facilities. It is important to understand how the components of a transportation facility are located in the real world or the proposed real world. The data, information, and knowledge have to be linked to specific locations and it is necessary to enable their efficient retrieval. While it is important that the model is sufficiently accurate and tied to a robust datum, it is also necessary to operate with adequate level of detail in correspondence to the phase of the project or level of project documentation. Furthermore, the structure and components of uildings differ from those used for road infrastructure facilities. Thus, there is a need for development of new representative terminology and its standardisation. However, the defining principles of BIM data management and exchange are still the same.

There is an increasing trend in publication of academic and nonacademic papers or case studies that are focused on BIM for road infrastructure. (Bradley et al., 2016), (Cheng et. al., 2016) and (Costin et. al., 2018) made a comprehensive literature review of the use of BIM in transportation infrastructure. The reviews showed that most of the studies or researches dealing with road infrastructure are focused on use of BIM in the pre-investment and investment phases of the road life cycle.

It is generally accepted that the transportation infrastructure needs constant monitoring to remain at the acceptable operational and safety level and to enable informed decisions of the authorities or decision makers. BIM principles can be used for these purposes due to the collection of data throughout the life cycle of a structure. Robust data frame and database, prediction of future behaviour and needs of infrastructure used in BIM can be therefore a decisive factor in maintenance and management process. Yet, only a few of reviewed articles, e.g. (Pevret et. al., 2000), (Chen, Shirole, 2006), (Platt, 2007), (Vonderohe, Hintz, 2010), (Kubota, Mikami, 2013), (Reeder, Nelson 2015), (Elnabwy et al., 2016), (Shindo et al., 2016), deals with use of BIM during the maintenance and operational phase of road life cycle. Furthermore, none of these contributions proposes to gather and implement new type of information into the BIM model during these phases.

Similarly, as is accepted that the deviations and changes have to be incorporated into the resulting BIM model, otherwise its content is pointless for subsequent management and maintenance, the important information gathered throughout the operational phase, such as accidents statistics or safety measures, should be also incorporated into the model. If this demand is not feasible, the data should be at least highly compatible with the structure of BIM model to improve the efficiency of decision-making and further investments. Out of the reviewed publications and study cases, none of the 400 contributions considered implementation of road safety data or accident information within the BIM model. This fact is rather surprising in comparison with current policies and increasing demands on the road safety worldwide.

\subsection{BIM in the Czech Republic}

In the Czech Republic, the Ministry of Transport of the Czech Republic (MOT) and its subordinate organizations, such as the Road and Motorway Directorate (RMD), are responsible for the construction, modernization and maintenance of the major transport infrastructures. The MOT is also responsible for introduction and revision of existing regulations in the field of transport infrastructure. These materials and their revisions, thus the revisions of the BIM requirements and the actual information models of buildings, are key to further implementation of necessary BIM methodology.

The BIM models started to be discussed more extensively in the Czech Republic in 2011 due to the activities of major design companies. In 2014, the European Union issued a irective 2014/24/EU on public procurement, which allowed contracting authorities across Europe to request the use of BIM when awarding public contracts. In the Czech Republic, this idea was implemented through Act No 134/2016, on public procurement. This opened a door for the implementation of BIM for civil infrastructure in the Czech Republic.

The BIM implementation strategy is currently being elaborated on the basis of Government Resolution No 958, on the importance of the Building Information Modelling (BIM) method for building practice in the Czech Republic and the subsequent proposals for its implementation. The government also set year 2022 as a milestone. After 1.1.2022, it will be mandatory to use BIM for over-limit public contracts financed from public budget. The obligation will be not only for the documentation and construction phases but also during the initiation and definition of the projects. Furthermore, it is planned to require all newly acquired road passports after this date in accordance to current BIM practices (IEG BIM, 2017).

The strategy is proposed with an aim to mitigate current difficulties preventing the effective use of the BIM methods in the Czech Republic and is gradually being established.

\subsection{Data transition in BIM processes}

The technical heart of the BIM method is the Common Data Environment (CDE), which includes all the information. That is not only the 3D model and its non-geometric data, but also all other documents, communication between the project participants and their processes in the various phases of the building's life cycle. However, based on the proposed methodology for selection of CDE, the RMD does not currently operate a sufficient solution and is only in initial phases of definition of requirements and expectations. Based on the available information, the concentrated data on a low level of detail will be available for not only managerial information system, but also for the needs of data integration and data sources of affected applications, such as BIM, CDE, or third-party applications (SFTI Expert Executive Team for BIM, 2019). 
As the Czech Republic is still in initial phases of implementation of BIM for road infrastructure, discussions on standardization format are also ongoing. In order to achieve interoperability based on public procurement a neutral and stable open data formats has to be used. It is planned to adopt the open Industry Foundation Classes (IFC) format as nationwide for the transmission of BIM models between individual actors in the transport infrastructure life cycle (IEG BIM, 2017). The IFC format is adopted in Czech Republic through the standard ČSN EN ISO 16739: 2017. The standard is based on the international standard ISO 16739.

The new IFC 5.0 format version should incorporate definitions for road infrastructure. The 5.0 version is however still being discussed and exists only in form of draft. The current version IFC 4.2 version, have only limited or missing semantics for transportation infrastructure facilities. The semantics and definitions are in both versions mostly focused on the preinvestment and investment phase. Thus, similarly as is the literature focus, it is entirely omitting the maintenance phase and potential inputs for road infrastructure acquired during its operation phase. This factor is crucial for further development of BIM models for transportation infrastructure. If the definition of BIM should be fulfilled, then the structure of the used CDE and data format should be able to incorporate additional information and data, which are acquired through reaming phases of the road life cycle. Important factor is however, the structure of these data and the possibility of their difference to the information used through planning and construction phases. (Eastmen, 2011)

\section{ROAD SAFETY ASSESSMENT}

Road safety is currently recognized by the WHO as a major global epidemic, and a large amount of research on road safety and safety data analysis is focused to mitigate its consequences, e.g. (Road Safety Manual, 2004), (Elvik et. al, 2009), (Commandeur et al., 2013), (Dupont et al., 2014), (UNECE, 2018). However, the effectivity of proposed measures is ultimately decided by the underlying data. The main base for evaluation of the road safety presents the traffic accident data and statistics. Nevertheless, analysis of these data must be accompanied by examination of the characteristics of the road infrastructure to obtain reliable and effective measures. The resulting outcomes afterwards directly affect the road itself, either in change of the traffic organisation, road equipment or in overall reconstruction of specific parts of the road.

Currently, there are two main approaches aiming to increase the safety on roads. Reactive approach which relies on analyses of available accident data and proactive approach which relies on the analysis of physical and operational characteristics of existing roads or road projects to identify actual and future safety deficiencies (Road Safety Manual, 2004).

For the reactive approach, relevant and sufficient data are crucial. The data consists from actual traffic accidents statistics and traffic volumes on particular roads. In the Czech Republic, a web based GIS application Statistical Overview of the Road Traffic Accidents in the Selected Administrative Territorial Unit is commonly used for assessment. The application is operated on the GIS portal of MOT. It enables statistical analysis of the traffic accident rate in frame of the specified administrative unit by the selected criteria (period, type of the road traffic accident). The data are directly imported from the database of Police of the Czech Republic (PCR). Furthermore, every year statistical yearbook of accident rate on roads is published for presenting statistics from previous year by the PCR. The traffic volumes can be obtained through a national traffic census that is periodically updated every 5 years or automatic counters that are installed on highways. The resulting traffic volume data are accessible through web based GIS application and are administered by the RMD.

As the knowledge evolves, safety actions are becoming more proactive in their nature. Various types of proactive measures have been long included in the practices of road authorities. The main tools are Road Safety Audit (RSA), Road Safety Inspection (RSI) and Road Safety Impact Assessment (RSIA). Wider spread of proactive approach within European countries was introduced by EU Directive 2008/96/EC, which defines their mandatory use on the TEN-T network and recommends their application for the whole road network.

The RSA deals with the design characteristics of new or reconstructed road infrastructure projects and RSI and RSIA deals with existing roads. The purpose is to make new, reconstructed and existing roads as safe as possible before construction starts and/or accidents occur. Both road safety audit and inspection focus solely on road safety without regard for other possibly conflicting objectives (Elvik et. al, 2009). The main aim is to ensure adequate level of road safety and provide additional source of information for the road authorities and decision makers.

From the perspective of BIM model for road infrastructure. The RSA is performed during all design and construction stages - from planning to early operation of the project. The necessary information for the evaluation are the same as information and data that are used for planning and design. The results and findings can be distributed to required participants with use of existing CDE.

The RSI and the RSIA are performed during the maintenance and operational phase of the road life cycle. In case of functional and precise BIM model, the supplementary information necessary for the RSI and RSIA can be obtained from its current form. However, the findings and identified safety deficits, especially for longer sections of the road network, cannot be in current frame implemented in a suitable form and in correspondence to their spatial location. Traditional approach of paper form is in this case highly inefficient and decrease the potential usage of the acquired information. Faculty of Transportation Sciences at the Czech Technical University in Prague (FTS, CTU in Prague) in close cooperation with RMD had therefore developed an effective and easy to use application for these purposes in 2015 .

\subsection{CEBASS - RSI generated data}

Department of Forensic Experts in transportation at the FTS, CTU in Prague developed in cooperation with RMD application that was subsequently named Central Register of Road Network Safety Analysis (CEBASS). It is a GIS application with web interface. The main aim was to develop a tool not only for the processing of data obtained during drive-through RSI, but also for effective management of the information, e.g. for presentation of registered risks, their statistical evaluation or subsequent indication of elimination. Overall, the web application contains information about more than 10000 trafficsafety defects on the Czech road network. The database covers almost $4,000 \mathrm{~km}$ and it is being used by the RMD for all performed RSI within the TEN-T network. 


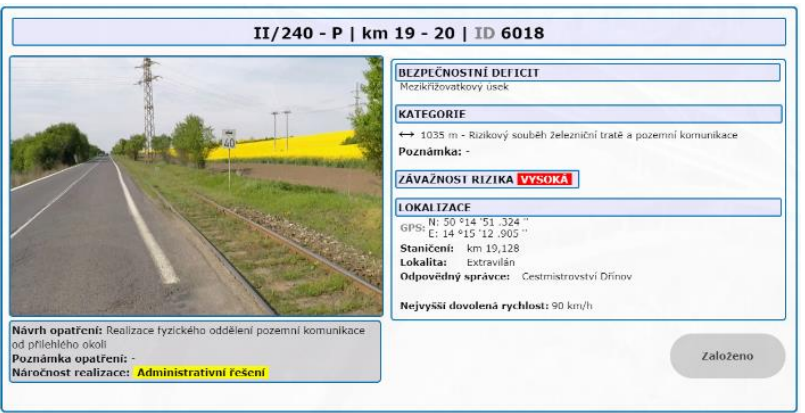

Figure 1. An illustrative example of identified safety deficit

Each record within the database represents an identified safety deficit and includes a standardized description, specification of the defect and its location, together with indication of the degree of severity and determination of the difficulty of implementing the proposed remediation measure. Specifications includes 14 main categories of the deficits that are further divided into more than 250 subcategories. Each record is accompanied by an illustrative photograph. Proposals for remediation measures conceptually outline for the road administrators how to achieve an adequate level of road safety in the area.
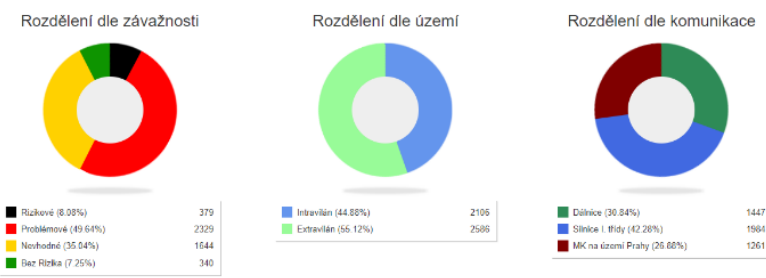

Figure 2. An Illustrative example of "Quick statistical overview" by severity, location of the deficits and road type

The application enables an effective control management due to intuitive and clear statistical evaluation. The road authority can use the graphical interface and possibilities to filter the identified deficits by their severity, type, proposed remedial measures or expected financial costs. Thus, it is enabled to perform an informed and effective prioritising and decision-making. The application also distinguishes several user roles that have different rights. For example, a selected professional public can only look at individual deficits sets. However, only responsible administrators can comment on the state of work.

\section{IMPLEMENTATION OF ROAD SAFETY ASPECTS IN ROAD BIM MODELS}

One of the differences between the road infrastructure and typical building is the requirement of adequate road safety for the road users. Even with application of complex technical standards, expert knowledge and modern approaches, the blackspots or locations with inadequate level of road safety may occur after the road is put into operation. Main reasons can be seen in the complexity and interconnection of various aspects during the road design and certain randomness in the behaviour of the road users (Elvik et. al, 2009). Thus, the current road safety practise is based on utilisation of the above-mentioned road safety approaches. Their aim is to identify the problematic or risky locations or design flaws, ideally proactively, and then implement proper countermeasures. It is one of the innate characteristic of roads and for successful and effective implementation of BIM on road infrastructure; the BIM model should be able to incorporate the necessary data and information. Due to the complexity of the safety assessment and wide range of information needed for accurate and precise analysis of traffic accidents or their causes, it is not possible or suitable to try to implement all the necessary data into the BIM of road infrastructures. However, one of the properties of BIM is that it can also be used as a repository for additional data, information, and knowledge that is generated during operation and maintenance. There are already examples of such principles in pavement management systems, bridge management systems, and similar knowledge bases (Jahren, 2015).

Desirable approach is to implement information that are closely connected to the road and its operation and ensure their compatibility with remaining information that are stored outside the BIM model. Traffic volumes identified on the road, identified deficiencies from RSI or RSIA or basic information about recorded accidents are examples of such data. Important factor is the necessity of geospatial reference of these data and their connection to already existing information within the database. The macroscopic tools, such as GIS applications managed by the MOT or RMD, should then aggregate this information from various projects or sources, similarly as the Statistical Overview of the Road Traffic Accidents in the Selected Administrative Territorial Unit or CEBASS application. The planned aggregation of several information sources in the CDE by RMD is in concord with the proposed solution.

(Bradley, 2016) identify the basic definitions that are necessary to properly and efficiently govern the information of a project as a need to define : data responsibility, data generator and data consumer. The proposed safety data, which should be incorporated into the BIM models of road infrastructure in Czech Republic, are mainly traffic volumes identified on the road, identified deficiencies from RSI or RSIA and basic information about recorded accidents. The overall responsibility of their acquisition and incorporation into the model is dependent on the data itself. The overall $\mathrm{CDE}$ and the projects of road infrastructures will be managed by RMD in future. Traffic volumes are detected with use of automatic counters that are administered by the road authority (RMD) or through a national traffic census. The contracting authority for the periodical census is also RMD. The RSI or RSIA are contracted through RMD and performed by certified safety auditors. Thus, the only data without direct connection to the RMD is information about traffic accidents. These data are currently acquired by the PCR and are already shared with the MOT, superior organisation of the RMD. The implementation of such data into the BIM model would lead to a higher value of non-graphical data, easier assessment of safety needs and improve the governance strategy of the road authorities.

\section{CONCLUSIONS}

Transportation infrastructure is an integral part of economic growth and social improvement of every country. Road infrastructures are connected with significant costs that are related to its full life cycle. Thus, a significant effort is required to preserve and maintain the facility as an asset. The road infrastructure requires an efficient and tailored management for the whole system. Maintenance of adequate road safety level and elimination of potential risks for all road user presents a major problem of a nation's transportation network. Traditional inspection and management systems are now inefficient due to extensive expansion of this network, fractured and mutually disparate information. Thus, there is an immediate 
need for shifting toward modern and automated management systems. Using BIM in correlation with emerging technologies for the management of infrastructure can help in more reliable, sustainable, and safer performance of the network while decreasing maintenance costs and risks.

While there are significant efforts for implementation of BIM models for road infrastructure, the implementation is mainly focused on the pre-investment and investment phase of the road life cycle. However, for every road infrastructure, it is important to observe the performance of the road, behaviour of road users and evaluate the resulting safety risk, to be able to correspond with adequate and effective measures and to secure sufficient level of safety. The paper discussed and proposed an implementation of the road safety aspects and statistics into the processes of BIM applications and strategies in the Czech Republic.

\section{REFERENCES}

Al-Mashta, S., Alkass, S., 2010: Integrated cost budgeting and estimating model for building projects. 54th Annual Meeting of the American Association of Cost Engineers International 2010, Vol. 1, Atlanta, GA, ISBN: 9781617388033 2010, 22-36.

Bradley, A., Li, H., Lark, R. Dunn, S., 2016: BIM for infrastructure: An overall review and constructor perspective. Automation in Construction, Volume 71, Part 2, 139-152. doi.org/10.1016/j.autcon.2016.08.019.

Commandeur, J.J.F., Bijleveldb, F.D., Bergel, R., Antoniou, C., Yannis, G., Papadimitriou, E., 2013: On statistical inference in time series analysis of the evolution of road safety. Accid. Anal. Prev., 60, 424-434.

Costin, A., Adibfar, A., Hu, H., Chen, S. S. 2018: Building Information Modeling (BIM) for transportation infrastructure Literature review, applications, challenges, and recommendations. Automation in Construction, Volume 94, pp. 257-281. doi.org/10.1016/j.autcon.2018.07.001.

Dupont, E., Commandeur, J.J., Lassarre, S., Bijleveld, F., Martensen, H., Antoniou, C., Papadimitriou, E., Yannis, G., Hermans, E., Perez, K., Santamarina-Rubio, E., Usami, D.S., Giustiniani, G., 2014: Latent risk and trend models for the evolution of annual fatality numbers in 30 European countries. Accid. Anal. Prev., 71, 327-336.

Eastman, C., 2011: BIM handbook: A guide to building information modeling for owners, managers, designers, engineers and contractors. 2nd ed., Hoboken, NJ, Wiley, ISBN:978-0-47054-137-1

Elnabwy, M., Kaloop, M., Elbeltagi, E., 2013:, Talkha steel highway bridge monitoring and movement identification using RTK-GPS technique. Measurement 46, 4282-4292. doi.org/10.1016/j.measurement.2013.08.014.

Elvik, R., Hoye, A., Vaa, T., Sorensen, M., 2009: The handbook of road safety measures (2nd ed.). Emerald, Bingley, United Kingdom. ISBN: 978-1-84855-250-0.

Ferne, B., 2006: Long-life pavements-a European study by ELLPAG. International Journal of Pavement Engineering, 7:2, 91-100. doi.org/10.1080/10298430600619059.
Gökçe, K.U., Katranuschkov, P., Scherer, R.J., 2006: IT supported construction project management based on IFC and ISO9001:2000. 6th European Conference on Product and Process Modelling - eWork and eBusiness in Architecture, Engineering and Construction, Valencia, ISBN: 9780415416221, 513-522.

Chen, S.S., Shirole, A.M.,2006: Integration of information and automation technologies in bridge engineering and management: extending state of the art. J. Transp. Res. Board, 1-24. doi.org/10.3141/1976-03.

Cheng, J.C.P., Lu, Q., Deng, Y., 2016: Analytical review and evaluation of civil information modeling. Automation in Construction, $\quad$ Volume 67, 31-47. doi.org/10.1016/j.autcon.2016.02.006

IEG BIM, 2017: BIM Implementation Strategy in the Czech Republic. Ministry of industry and trade https://www.mpo.cz/assets/en/construction-and-rawmaterials/bim/2019/3/Koncepce-zavadeni-metody-BIM-vCR_EN.pdf (1 November 2019).

Jahren, C.T. 2015: Advances in civil integrated management, Rep. No. NCHRP Project 2068A, Scan 13-02, Transportation Research Board of the National Academies, Washington, DC, http://onlinepubs.trb.org/onlinepubs/nchrp/docs/NCHRP2068A_13-02.pdf (1 November 2019).

Kubota, S., Mikami, I., 2013: Development of product data model for maintenance in concrete highway bridges. J. Appl. Comput. Civil Eng. 2013 (11) 1-12. doi.org/10.1155/2013/148785.

Peyret, F., Jurasz, J., Carrel, A., Zekri, E., Gorham, B., 2000: The computer integrated road construction project. Automation in Construction, 9 (5) 447-461. doi.org/10.1016/S09265805(00)00057-1.

Platt, A., 2007: 4D CAD for highway construction projects. Rep. No. 54, Computer Integrated Construction Research Program, Pennstate

University https://www.engr.psu.edu/ae/cic/publications/TechReports/TR_ 054_Platt_2007_4D_for_Highway.pdf (1 November 2019).

Reeder, G. A., Nelson, G. D., 2015: 3D engineered models for highway construction: the Iowa experience. Rep. No. RB33-014, Iowa Department of Transportation https://lib.dr.iastate.edu/intrans_reports/130 (1 November 2019).

Road Safety Manual, 2004:, Recommendations from the World Road Association (PIARC), PIARC Technical Committee on Road Safety (C13).

See, R., Karlshoej, J., Davis, D., 2012:An Integrated Process for Delivering IFC Based Data Exchange. https://standards.buildingsmart.org/documents/IDM/IDM_guide -IntegratedProcess-2012_09.pdf (1 November 2019).

SFTI Expert Executive Team for BIM, 2019: METODIKA pro výběr společného datového prostředí (CDE) - prozatímní verze. https://www.sfdi.cz/soubory/bim/2019_09_cde.pdf November 2019).

Shindo, K., Matsuzaka, T., Mizuguchi, K., Koshizuka, N., Ishikawa, Y. ,2016: Data model and method of database federation for expressway infrastructure management. Proc. In 
International Conference on Computing in Civil and Building Engineering (ICCCBE), Jul. 6-8, Osaka, Japan, 1148-1154 http://www.see.eng.osaka-

u.ac.jp/seeit/icccbe2016/Proceedings/Full_Papers/145-333.pdf

(1 November 2019).

UNECE, 2018: SafeFITS - Safe Future Inland Transport Systems, United Nations publication issued by the Economic Commission for $\quad$ Europe (ECE). http://www.unece.org/fileadmin/DAM/trans/events/docs/SafeFI TS_Final_Report.pdf (1 November 2019).

Vonderohe, A., Hintz, C., 2010: 3D design terrain models for construction plans and GPS control of highway construction equipment. Rep. No. CFIRE 02-05, National Center for Freight \& Infrastructure Research \& Education, University of Wisconsin, http://digital.library.wisc.edu/1793/55940 (1 November 2019). 